\title{
Desenvolvimento turístico e gestão participativa em sítios históricos urbanos: uma contribuição teórico-conceitual sobre o cenário brasileiro
}

Júlia Erminia Riscado*

\section{Resumo}

Cada vez mais próximo a setores empresariais, o turismo tem se tornado alvo de recorrentes críticas por se distanciar de setores sociais na elaboração e no acompanhamento de políticas públicas e/ou programas de recuperação de sítios históricos, especialmente em áreas urbanas. Com base nesse cenário, o presente artigo tem como objetivo observar as transformações ocorridas nos sítios históricos urbanos brasileiros a partir de uma análise teórico-conceitual. Para tal, serão apresentados debates bibliográficos sobre as noções de gestão participativa e de turismo. Em ambos os casos pretende-se traçar um diálogo com a questão dos processos de refuncionalização nas cidades contemporâneas. Posteriormente, analisaremos o planejamento do turismo no Brasil e as perspectivas adotadas que interferem de modo determinante na elaboração de estratégias e de medidas para o desenvolvimento do setor na atualidade. Espera-se, com isso, contribuir para a reflexão acerca dos caminhos e possibilidades na introdução de mecanismos participativos na gestão de sítios históricos urbanos.

\section{Palavras-chave}

Gestão participativa. Turismo. Brasil.

\begin{abstract}
Increasingly closer to business sectors, tourism has become the target of recurrent criticism for distancing itself from social sectors in designing and monitoring public policies and / or programs for restoring historic sites, especially in urban areas. Based on this context, the present article aims to observe the transformations that took place in Brazilian urban historic sites through a theoretical-conceptual analysis. For this, we will present bibliographic discussions regarding the sense of participatory management and tourism. In both cases it is intended to draw up a dialogue regarding the question of the refunctionalization processes in contemporary cities. Subsequently, we will analyze the planning of tourism in Brazil and the perspectives adopted that determinedly interfere in the elaboration of strategies

\footnotetext{
* Júlia Erminia Riscado é Bacharela e Licenciada em História pela Universidade Federal Fluminense (UFF), Mestra em História pela Universidade Federal do Estado do Rio de Janeiro (UNIRIO) e Doutora em Ciência Política pela Universidade Federal Fluminense (UFF). E-mail: julia_riscado@yahoo.com.br.
} 
and measures for the development of the sector in the present time. We therefore hope to contribute to the reflection regarding the ways and possibilities in the introduction of participatory mechanisms in the management of historical urban sites.

\section{Keywords}

Participatory mechanisms. Tourism. Brazil.

\section{Centros históricos: espaços de permanência e mudança nas cidades}

A cidade contemporânea, configurada por espaços de conflitos e de constante negociação entre diversos interesses, tende a refletir a inconstância do momento vivido. O surgimento progressivo de novas linguagens e de espaços alternativos evidencia em qualquer ação de defesa e valorização dos legados físicos do passado um imperativo para as sociedades contemporâneas e um desafio para os territórios.

Nesse sentido, a refuncionalização do passado torna-se fundamental na compreensão do papel dos centros históricos no contexto de desenvolvimento urbano recente (FORTUNA, 1997; PEREIRA, 2002). O processo de promoção do patrimônio nesses espaços, quase sempre vinculada à uma lógica empresarial, converte a marca de tradição do patrimônio em capital de inovação.

Por outras palavras, a expressão "centro histórico", mais do que remeter para um objeto ou para um espaço, converte-se em representação de alguma coisa. Essa metalinguagem do património, de que a expressão "centro histórico" faz parte, representa tudo o que nos arriscamos a perder no contexto de uma urbanização galopante, incluindo aquilo que, por vezes, nunca se teve: o espaço público, a qualidade de vida, as referências identitárias, a cidade à escala humana. Em suma, representa as bases de uma cidade culturalmente sustentável. Nesta dimensão de metalinguagem do patrimônio, a expressão "centro histórico" não pode deixar de ser encarada como um recurso retórico das políticas de reabilitação urbana, encerrando em si própria muitas das ideologias que sustentam essas políticas. (PEIXOTO, 2003, p. 213) 
A partir da visibilidade seletiva de elementos emblemáticos das zonas urbanas antigas, o turismo passou a ser elemento fundamental na competitividade entre cidades ao explorar suas vantagens específicas (HARVEY, 2005), estimulando novas atrações de consumo e entretenimento. Essa postura empreendedora adotada por administrações nacionais e locais, em parceria com agentes privados, tornou-se um modelo de desenvolvimento urbano compartilhado nas mais diferentes realidades ao redor do mundo (HARVEY, 2005; PEIXOTO, 2003).

Observa-se, com isso, uma renovação identitária, que retoma a condição de centralidade ao centro histórico a partir de um discurso que legitima investimentos financeiros e a adoção de instrumentos legais que justifiquem intervenções urbanísticas e políticas no local. De acordo com Carlos Vainer (2009), a ideia de consenso expressa nos planos estratégicos e projetos formulados pelos governos locais parte da consciência de crise. Ou seja, da percepção comum entre os principais atores e a maioria dos cidadãos de uma situação urbana a ser superada, por exemplo, a degradação dos centros históricos e a congestão do centro moderno. Dessa maneira, a liderança política procuraria investir na ideia de unidade, colocando-se acima dos partidos e das paixões, e passaria a estar cada vez mais próxima das características específicas das lideranças empresariais.

Ao serem retirados de uma situação de deterioração arquitetônica, econômica e social, os centros históricos recebem através da atividade turística o principal meio de garantir sua sustentabilidade. Em uma perspectiva crítica, entretanto, o turismo passa a ser considerado um setor que homogeneíza os centros históricos, contaminando negativamente sua cultura, economia e arquitetura (CARRIÓN, 2005; CHOAY, 2002; PEIXOTO, 2003).

Um dos efeitos imediatos desse processo, como aponta Paulo Peixoto (2003), é a estetização das práticas quotidianas dos indivíduos e dos locais que caracterizam o cotidiano dos núcleos urbanos centrais. Quando recebem o status de produto ou de imagem a ser consumida, os centros históricos adentram em um ciclo de iniciativas urbanísticas que priorizam o embelezamento de fachadas e estimulam a criação de eventos atrativos que combinam o tradicional com o festivo.

Os "centros históricos" reabilitados estão, em maior ou menor grau, a converter-se em palcos de sociabilidades espectacularizadas e de encenação da vida quotidiana, constituindo-se como uma espécie de nova realidade alegórica das cidades. Alegoria esta 
que se manifesta de forma tripartida. Por um lado, os "centros históricos" são cada vez mais apresentados como a expressão concreta de uma ideia de espaço público que permite que a cidade seja imaginada e transformada a partir do seu passado. Assim, sob forma figurada da imbricação entre consumo e lazer, os "centros históricos" são uma alegoria desse espaço público, supostamente perdido que urge recuperar. (PEIXOTO, 2003, p. 222)

Ao priorizar um estilo de vida a ser vendido para turistas, os projetos de recuperação e de revitalização se distanciam dos indivíduos da cidade. Deixam de exercer sua centralidade simbólica para a cidade como espaços de encontros e do convívio das diferenças para se transformarem em espaços cenográficos (BAPTISTA; PUJADAS, 2000; CHOAY, 2002). Tal dissonância amplia o questionamento sobre as políticas e programas aplicados nos centros históricos.

É certo que a emergência de uma economia vinculada ao turismo e ao lazer proporcionou o surgimento e a dinamização de determinadas atividades culturais e econômicas. Todavia, percebe-se em grande parte dos projetos de revitalização e de desenvolvimento turístico a pouca ou a total ausência de identificação coletiva da população local com os centros históricos.

A noção de gestão participativa, tratada a seguir, pode ser compreendida como um instrumento alternativo a ser considerado pelo urbanismo. Os processos de intervenção para os núcleos urbanos históricos ainda carecem de um planejamento que tenha como alvos a coletividade e a articulação dos diferentes grupos culturais, sociais e econômicos.

Um dos efeitos imediatos de incorporar o modelo de gestão participativa aos projetos de reabilitação de centros históricos está no reconhecimento da pluralidade de usos do espaço público. Os valores e sociabilidades passam a ser integralmente respeitados nesse processo, deixando de lado as "cenografias operísticas" (BAPTISTA; PUJADAS, 2000, p. 302) que caracterizam as inciativas atuais pautadas na exploração turística intensiva dos centros históricos.

\section{0 conceito de gestão participativa e seus reflexos na relação Estado-sociedade}

Com o intuito de contribuir para o debate acerca dos desafios no desenvolvimento e na gestão das cidades, cabe ressaltar o aumento do 
poder político de entidades subnacionais e da ampliação de iniciativas de consolidação do "empoderamento" das comunidades locais a partir da adoção de um projeto político democratizante e participativo. Como apontou Celina Souza (2004), ao priorizar uma gestão participativa, as administrações locais estariam alinhando-se ao princípio da participação direta do cidadão na gestão pública, estabelecido na Declaração dos Direitos do Homem, na qual "todo homem tem o direito a tomar parte no governo de seu país diretamente, ou por intermédio de representantes livremente escolhidos" (NAÇÕES UNIDAS, Art. XXI, inciso I, 1948, p. 1).

Todavia, é preciso destacar que a noção de gestão participativa tem origem na administração empresarial, sendo uma estratégia adotada pelas empresas de envolverem seus funcionários no processo de produção com a finalidade de se tornarem mais competitivas. A complexificação do cenário empresarial globalizado passou a exigir dessas organizações a adoção de um paradigma gerencial baseado em funções descentralizadas, participativas, interdependentes e integradas, não cabendo mais a perspectiva mecanicista de outrora. A abertura de novos mercados, as inovações tecnológicas e a internacionalização de atividades foram alguns dos principais motivos dessa mudança comportamental nas empresas (PREDEBON; SOUSA, 2003).

Buscando melhorar a utilização dos recursos na produção, foram estabelecidas regulações coletivas baseadas na premissa de que os indivíduos se identificassem com os propósitos das empresas, tendo maior atuação no processo de desenvolvimento empresarial. Ao investir no relacionamento com os funcionários, as empresas conseguiriam estimular uma postura mais ativa desses indivíduos no processo de produção e gestão da produção. Nesse sentido, o termo gestão participativa no contexto empresarial pode ser compreendido como a "forma de gestão em que um ou poucos administram, utilizando um grupo de trabalho ou o coletivo como um todo" (PREDEBON; SOUSA, 2003, p. 3).

Na administração pública, essa lógica se consolida na participação ativa de grupos da sociedade civil na gestão pública. Entretanto, como apontou Evelina Dagnino, esse processo não se deu de modo contínuo por estar relacionado à construção democrática dos governos:

(...) o processo de construção democrática não é linear, mas contraditório e fragmentado. Além disso, demonstra também que esse processo se vincula a uma multiplicidade de fatores, 
eliminando qualquer possibilidade de conceber a sociedade civil como demiurgo do aprofundamento democrático. (DAGNINO, 2002, p. 279)

Segundo Dagnino (2002), ainda que em determinados momentos compartilhem os mesmos interesses, Estado e sociedade civil estabelecem um diálogo quase sempre conflituoso. Tal situação poderia ser explicada pela existência de aspectos presentes em ambas as partes que impediriam a ampliação da participação da sociedade civil na gestão pública.

$\mathrm{Na}$ esfera estatal, a instabilidade política dos projetos, a pouca transparência e acesso a informações, a falta de recurso e uma burocracia excessiva caracterizariam dificuldades estruturais à plena participação popular. Enquanto no âmbito da sociedade civil, a autora destacou a falta de capacitação técnica e política para defender suas demandas e o perigo da cooptação ou da dependência de um agente qualificado como entraves nesse processo.

Diante desse cenário, Dagnino (2002) considera como maior desafio dos regimes democráticos contemporâneos o estabelecimento de consenso entre os diferentes agentes em torno de um projeto político. Nesse sentido, os espaços públicos tornam-se fundamentais para o reconhecimento da pluralidade e articulação das diferenças, uma vez que abririam caminho para a configuração do interesse público.

Jean Cohen e Andrew Arato (1992) também se voltaram à emergência de experiências participativas a partir da década de 1980. Ao analisarem a importância do ressurgimento e do fortalecimento de organizações civis para a viabilidade da democracia, os autores afirmaram que somente a partir da negociação entre diversos agentes seria possível estabelecer uma transformação nas relações de poder.

Embora não exerçam diretamente o poder político, grupos e organizações de caráter civil poderiam influenciar as decisões dos governos. Até mesmo, determiná-las. Nesse sentido, a ideia de complementaridade passaria a ser apresentada como aspecto fundamental para o entendimento da relação Estado e sociedade civil.

De acordo com Carlos Milani (2008), seria preciso atentar para os diferentes contextos em que o discurso de participação política foi apropriado pela Administração Pública. Em alguns casos, essa preocupação surge no bojo da crise de um modelo assistencialista de Estado, que predominou até meados da década de 70 nos países europeus e até os anos 80 nos países 
latino-americanos. A participação dos cidadãos na formulação e gestão de políticas públicas passaria a ser compreendida como "uma possível crise do bem-estar e à necessidade de rever as relações entre o governo e a sociedade na definição de estratégias de desenvolvimento local" (MILANI, 2008, p. 557).

Já nos casos de democracias representativas, procurou-se estabelecer um modelo que melhor compreendesse a coexistência de diferentes escalas de governo. Além disso, a participação social era percebida como um dos elementos a compor um projeto de ressignificação do conceito de público. Ou seja, seria uma reforma do Estado baseada na participação de diferentes atores, tratando-a com igual relevância no processo de participação.

Entretanto, segundo Elenaldo Teixeira (2001), esses dois aspectos seriam complementares quando se trata do conceito de participação política. Isso porque, a partir de um processo de construção de identidades e reivindicação de novas demandas, novos atores se incorporariam à sociedade política, lutando por seus direitos, reconhecimento e atuação na elaboração de políticas públicas, e formariam uma nova cultura política.

Com a crise do Estado, o desprestígio e a burocratização do sistema partidário, o agravamento dos conflitos sociais e a crescente conscientização de vários segmentos sociais, desenvolvem-se novas alternativas de participação, novas áreas de relações sociais (homem/mulher, etnias), incorporando-se temas até aí fora da problemática política tradicional. Exercita-se assim uma outra lógica - a da solidariedade e busca de um consenso normativo em relação a questões básicas, tais como meio ambiente, exclusão social, cooperação internacional, possibilitando-se o surgimento de novos tipos de participação, mais ampla, inclusive de conteúdo mais contestador, formando-se uma nova cultura política em que se valorizam a ação coletiva, a construção de identidades, a criação e efetivação de direitos, o enfrentamento dos problemas cotidianos. (TEIXEIRA, 2001, p. 28).

Embora esse debate tenha ganhado força durante os anos 1980, foi na década seguinte que a participação política se tornaria um dos principais princípios organizativos. Entre organismos internacionais passou-se a notar a necessidade de incorporação de diferentes atores políticos e sociais no monitoramento de questões que ultrapassam os limites nacionais, buscando preservar os princípios democráticos. Ao reconhecer os impactos da globalização nos contextos locais, essas organizações buscaram propor 
soluções junto a populações de diversos países, a fim de estabelecerem um modelo de gestão pública local.

Além das orientações de organismos nacionais e internacionais, houve um esforço por parte de governos locais em promover estratégias de inovação a partir da participação dos cidadãos. Como consequência dessas iniciativas, alguns grupos e movimentos sociais perceberam a criação de um campo favorável para recuperar reivindicações históricas, por exemplo, as relacionadas à gestão de políticas urbanas (MILANI, 2008).

Contudo, os processos locais de participação social encontrariam dois limites críticos:

Em primeiro lugar, a participação de atores diversificados é estimulada, mas nem sempre é vivida de forma equitativa. $\mathrm{O}$ termo "parceria" é corriqueiro nos discursos políticos dos atores governamentais e não governamentais, mas sua prática efetiva parece ter dificuldades em influenciar os processos de deliberação democrática local. Em segundolugar, os atores não governamentais (e somente alguns deles) são consultados e solicitados durante o processo de tomada de decisões, participando, assim e no melhor dos casos, somente antes e depois da negociação. A participação praticada dessa forma pode aumentar a qualidade da transparência dos dispositivos institucionais; contudo, ela não garante, de modo necessário e automático, a legitimidade do processo institucional participativo na construção do interesse coletivo. (MILANI, 2008, p. 555).

Ademais, muitas lideranças sociais foram incorporadas à sociedade política através da institucionalização de algumas conquistas alcançadas por movimentos sociais e da criação de partidos políticos com programas mais afinados aos valores democráticos. Com isso, a década de 1990 passou a ser compreendida por alguns autores como um período de certo refluxo dos movimentos sociais.

Todavia, a retração dos movimentos sociais pode ser entendida como um novo momento no processo participativo, em que alguns atores sociais passam a fazer parte de novos espaços institucionais. Sua incorporação representaria um cenário novo e, por isso, mais complexo diante daquele consolidado na década de 1980. Porém, não poderia ser considerado menos válido dentro dos princípios da gestão participativa no contexto da administração pública. 
Independentemente das formas que se pode revestir, a participação significa "fazer parte", "tomar parte", "ser parte" de um ato ou processo, de uma atividade pública, de ações coletivas. Referir "a parte" implica pensar o todo, a sociedade, o Estado, a relação das partes entre si e destas como o todo e, como este não é homogêneo, diferenciam-se os interesses, aspirações, valores e recursos de poder. Apresenta-se assim o problema de como responder aos interesses gerais em face do particularismo e do corporativismo dos atores, exigindo-se condições objetivas e subjetivas e espaços públicos onde possam ocorrer negociações e compromisso para que as argumentações, livremente expostas, permitam chegar-se a um consenso traduzível em decisões no sistema político. (TEIXEIRA, 2001, p. 27).

\section{0 conceito de turismo e o planejamento do setor no Brasil}

De acordo com a Organização Mundial do Turismo (OMT), o turismo compreende todas "as atividades realizadas pelas pessoas durante suas viagens e estadias em lugares diferentes de seu entorno habitual, por um período de tempo consecutivo inferior a um ano, tendo em vista lazer, negócios ou outros motivos" (OMT, 1995, p. 1). Entretanto, há um extenso debate acadêmico sobre o conceito a partir de interlocuções com diferentes problemáticas e áreas acadêmicas, tais como antropologia, sociologia e urbanismo (URRY, 1996; BEEHO; PRENTICE, 1997; TRIBE, 1997).

De acordo com John Urry (1996), por exemplo, a atividade turística seria um período de exceção, uma vez que o indivíduo deixaria de exercer suas atividades cotidianas a partir do momento em que sai do seu domicílio ou ambiente de trabalho. Desse modo, as práticas sociais desenvolvidas no turismo seriam percebidas como lazer.

O entendimento sobre a experiência turística de John Urry converge com a linha de análise apresentada por Valene Smith (1989), que identificou o lazer como um segmento fundamental no turismo. Entre suas considerações, Smith aponta o turismo cultural como sendo aquele em que turistas procuram lugares "pitorescos", distanciando-os de seus problemas cotidianos.

Ted Silberberg (1995, p. 361) ampliou um pouco mais a noção de turismo cultural ao defini-lo como o ato de "visitação por pessoas de fora da comunidade receptora motivada no todo ou em parte por interesse em aspectos históricos, artísticos, científicos ou de estilo de vida e de herança 
oferecidos por uma comunidade, região, grupo ou instituição". Nesse sentido, é necessário considerar o papel da noção antropológica de cultura para o conceito de turismo cultural apresentado, uma vez que reconhece diferentes códigos, saberes e práticas entre as diferentes configurações culturais e sociais.

Entretanto, a noção de turismo cultural apresentada por Bob Mc Kercher e Hilary Du Cros (2003) parece ser a mais adequada para refletir sobre a gestão do patrimônio na atualidade. Ao definirem turismo cultural como um segmento inserido no mercado turístico, os autores procuraram identificar as deferentes motivações e níveis de envolvimento sobre as atrações turísticas entre os diversos perfis socioculturais que compõem esse segmento. Para isso, a noção de atração turística cultural utilizada ao longo da pesquisa se baseia no conceito de patrimônio cultural da International Commission on Monuments and Sites (ICOMOS):

Patrimônio cultural é um conceito amplo que inclui bens tangíveis, como ambientes naturais e culturais, incluindo paisagens, locais históricos, sítios e ambientes construídos, assim como bens intangíveis, como coleções, práticas culturais passadas e atuais, conhecimento e experiências de vida. Exemplos de patrimônio tangível incluem museus, prédios históricos, sítios religiosos e talvez parques temáticos, se eles têm um foco patrimonial, enquanto o patrimônio intangível inclui coleções, performances e festivais. Elas não incluem, no entanto, atrações turísticas que não têm um foco cultural ou patrimonial claro e reconhecível. (MC KERCHER; DU CROS, 2003, p. 48).

Ainda que o objetivo do estudo tenha sido apresentar uma tipologia dos turistas no segmento do turismo cultural, cabe destacar que os autores utilizaram uma abordagem teórica proveniente do campo empresarial para analisar a dinâmica do campo turístico. Tal leitura reflete a importância econômica progressiva do setor turístico no contexto internacional.

A partir do aumento do fluxo turístico em sítios históricos e ambientais surgiu a necessidade de ampliar ou criar infraestrutura hoteleira nas localidades. Com isso, a relação entre o turismo e o patrimônio se consolidou ainda mais, sendo basilar para a legitimação e o desenvolvimento do setor turístico.

Como apontou Francisca Hernández (2002), o turismo passaria a ser considerado um campo estratégico para o incremento das economias 
nacionais. E, consequentemente, o patrimônio nacional tornar-se-ia elemento fundamental nesse processo:

Em uma época em que a Europa começa a estimular e potencializar a sociedade de consumo, como fruto da ruptura social e econômica que predominou nos anos 60, não é de se estranhar que a noção de patrimônio cultural venha enriquecendo cada vez mais, integrando não somente paisagens naturais e sítios históricos, mas também antigos edifícios industriais. Tudo isso tornará possível que o patrimônio passe a adquirir uma função econômica importante e que o turismo cultural se transforme em um meio fundamental para apresentar as diferentes ofertas feitas ao visitante. (HERNANDEZ, 2002, p. 365).

No caso dos sítios históricos, além da construção de infraestrutura local, o turismo estimulou a produção e promoção de representações sociais da cidade. Segundo Arley Andriolo (2009), diferentemente da "cidade do habitante", a noção de cidade histórica adotada pelo turismo seria formulada a partir de um ideal hegemônico. Ou seja, por ser composto por instâncias governamentais, empresariais e representantes de grupos da sociedade civil, o campo do turismo representaria em escala reduzida as lutas e estratégias simbólicas que configuram a estrutura social.

Desse modo, seria possível afirmar que os atrativos turísticos seriam construções artificiais, apropriadas e reelaboradas de acordo com o público consumidor. Sozinhos, os elementos históricos não seriam suficientes para criar e redirecionar possibilidades de uso e apropriação da cidade para o turismo.

Admite-se a existência de uma interface entre o campo da produção erudita e o campo do turismo, possibilitando a constituição de produtos turísticos. Os discursos e documentos visuais produzidos pelos intelectuais são extraídos de seu campo originário e reproduzidos conforme as necessidades do campo turístico. No entanto, os significados são utilizados apenas em parte, não somente reproduzidos de modo imediato, passam por interesses de grupos hegemônicos do próprio campo turístico. Assim, a "cidade histórica turística" emerge desde a sua gestação nos escritos dos viajantes, da apreciação de estudiosos, passando pelo redirecionamento imprimido segundo os interesses de agenciadores do turismo e governantes, para se tornar então objeto da percepção do turista (ANDRIOLO, 2009, p. 161). 
A compreensão do ambiente urbano feita por Arley Andriolo reconhece a cidade como um "artefato produzido socialmente em diversos momentos" (ANDRIOLO, 2009, p. 161). O espaço urbano representaria a diversidade e as tensões da experiência social vivida, sendo o turismo um entendimento parcial da realidade nas cidades e centros históricos.

Atualmente, os centros históricos são apresentados por seus gestores locais como zonas emblemáticas para a história das cidades. Entretanto, o caráter policêntrico das cidades contemporâneas retira dessas áreas a percepção das regiões centrais como principal espaço de convivência coletiva (BARREIRA, 2010).

Os projetos de revitalização e requalificação elaborados por administradores locais, setores empresariais e alguns grupos da sociedade civil passam a expressar a intenção em "conferir aos locais públicos formas dinâmicas de utilização, baseadas em investimentos comumente associados a comércio e lazer" (BARREIRA, 2010, p. 255). O turismo, portanto, apareceria como uma alternativa de utilização dessas áreas ao incorporar novos usos aos centros históricos.

No Brasil, seguindo uma tendência internacional que ultrapassa os limites do setor turístico, a descentralização definiu a forma como as políticas de turismo foram estruturadas no país. Tal postura iniciou-se com o Programa Nacional de Municipalização do Turismo (PNMT) em 1994.

Durante o governo Itamar Franco, mediante a Portaria 130, de 30 de março de 1994, do Ministério da Indústria, Ciência e Tecnologia, foi criado o Comitê Executivo do PNMT (CRUZ, 2000). Entretanto, somente em 1996, no então governo Fernando Henrique Cardoso, o Programa foi oficializado e passou a ser executado pela Embratur ${ }^{1}$.

A inovação na proposta do PNMT estava em dar enfoque participativo ao planejamento do turismo no país. Para isso, foi elaborada uma metodologia a partir da fusão de técnicas Metaplan² e do método ZOPP, ambos criados na Alemanha entre as décadas de 1970 e 80. Seu objetivo

\footnotetext{
${ }^{1}$ Criada em 1966, é uma autarquia especial do Ministério do Turismo responsável pela execução da Política Nacional de Turismo.

${ }^{2}$ Metaplan é um conjunto de ferramentas de comunicação para serem usadas por grupos em busca de ideias e soluções, para a formulação de objetivos, recomendações e planos de ação.

${ }^{3} \mathrm{O}$ método ZOPP de planejamento e avaliação de projetos por objetivos (Ziel-Orientierte Projekt Planung) foi criado pela Cooperação Técnica Alemã (GTZ) e é utilizado para o planejamento participativo de projetos nas mais diversas áreas. O ZOPP é um método com etapas sucessivas, interligadas por meio de reuniões (oficinas) conduzidas por um moderador (facilitador).
} 
consistiu em capacitar os municípios brasileiros de modo que criassem e mantivessem os Conselhos Municipais de Turismo com a participação ativa das comunidades locais na participação e gestão do PNMT (PEREIRA, 2000).

Baseado nos princípios da descentralização, da sustentabilidade, da parceria, da mobilização e da capacitação dos atores envolvidos, o PNMT se mostrou uma iniciativa que pretendia atualizar a gestão do turismo. Para isso, procurou estimular a formulação de políticas e de metodologias de planejamento do turismo adequadas às diferentes realidades do país.

Entretanto, como apontou Leandro Brusadin (2005), há muita controvérsia sobre os efeitos positivos e negativos do programa. A adoção do método ZOPP, por exemplo, pode ser pouco adequada à realidade brasileira. Por ter sido elaborado na Alemanha, o modelo considerou a realidade educacional e econômica do país europeu. Desse modo, seria inadequado utilizá-lo no planejamento do turismo do Brasil.

Em contrapartida, a medida possibilitou toda uma discussão crítica a respeito da atividade turística. Com o debate sucedido foi possível observar, inclusive, as lacunas do PNMT que acabavam dificultando a execução do planejamento participativo e decentralizado proposto inicialmente.

Um dos problemas observados foi a falta de clareza na definição dos critérios adotados para determinar a potencialidade turística de uma dada localidade. $\mathrm{O}$ abandono da metodologia de inventário turístico e a adoção do RINTUR [Relatório de Informações Turísticas], identificada na pesquisa como substituto para determinação dessa potencialidade, evidenciam essa falta de critérios técnicos. O RINTUR é inadequado para avaliação da potencialidade turística, e sua adoção permite a ocorrência de interferências de variáveis políticas nas avaliações (...). Não menos relevante é a ingerência política na elaboração dos planos e projetos que têm como efeito o bloqueio da participação efetiva da sociedade civil. Por último, fica a questão da falta de recursos disponíveis para aplicação nos planos e projetos turísticos, o que acaba por desmotivar e desmobilizar a população diante de outras necessidades mais prementes. (BRUSADIN, 2005, p. 109).

Em 2004, o PNMT foi substituído pelo Programa de Regionalização do Turismo (PRT). Posteriormente, o PRT constituiu um dos macroprogramas do Plano Nacional de Turismo (PNT) 2007-2010. São eles: Planejamento e Gestão; Informação e Estudos Turísticos; Logística de Transportes; 
Regionalização do Turismo; Fomento à Iniciativa Privada; Infraestrutura Pública; Qualificação dos Equipamentos e Serviços Turísticos; Promoção e Apoio à Comercialização, e Implementação do PNT (BRASIL, 2007).

Diferentemente do PNMT, o PRT ultrapassou a esfera municipal para atuar em âmbito regional. Com o intuito de ordenar, diversificar e qualificar a oferta turística do país, o programa utilizou como principal estratégia a roteirização turística.

Ao agrupar os municípios com atrativos e potenciais similares em regiões, essa medida tem como objetivo ampliar as opções turísticas e a atratividade do país. Portanto, o PRT atua como um modelo de gestão pública coordenada, integrada e compartilhada nas esferas federal, estadual e municipal. Além disso, pretende explorar a cooperação entre diversos atores da sociedade civil e do setor empresarial (BRASIL, 2007).

Ao estruturar a oferta turística por meio da roteirização, o PRT exige dos atores envolvidos um aprofundamento sobre o cotidiano e a história local. Com base no conhecimento dos potenciais atrativos da região, tornase possível promover e diversificar o turismo, dinamizar as economias e potencializar a competitividade dos produtos turísticos locais (BRASIL, 2007).

Assim, a atividade turística é apresentada no PRT como um produto, e a roteirização como uma ferramenta de marketing local, capaz de promover uma determinada região e torná-la mais atrativa e competitiva diante dos demais destinos turísticos. Nesse sentido, como apontou Miguel Bahl (2003, p. 143), a elaboração de roteiros turísticos traz "implícita a necessidade de reunir o maior número de atrativos que os tornem realmente peculiares no âmbito da concorrência".

A noção de turismo apresentada pelo PRT aparece bastante atrelada ao aspecto econômico e ainda coloca a arquitetura, o ambiente, as práticas e as expressões locais na condição de instrumentos para incrementar a oferta turística de uma dada região. Percebe-se, com isso, que as mudanças no setor do turismo acontecem de modo mais intenso nas ferramentas de gestão e menos em sua filosofia e conceitos.

\section{Considerações Finais}

Nas últimas décadas do século XX houve uma mudança na postura adotada por gestores públicos e técnicos quanto à elaboração e implementação de políticas públicas para sítios históricos urbanos. Com o intuito de conter os 
impactos negativos das atividades turísticas nessas localidades, passou-se a investir na incorporação de mecanismos participativos e sustentáveis às propostas de intervenção nos sítios históricos urbanos.

Ao incluir diferentes atores sociais nas etapas de concepção, aplicação e monitoramento dos planos de recuperação, tais iniciativas abririam caminho para a emergência de um novo modelo de gestão de sítios históricos urbanos. Com isso, passariam a ser consideradas questões relativas ao cotidiano dessas comunidades locais, como o respeito à diversidade cultural e a garantia de habitação. Seus desafios e lacunas expuseram, contudo, o caráter ainda incipiente de tais iniciativas.

Como foi observado, essa perspectiva refletiu um momento de crescente reivindicação por parte de movimentos e de organizações sociais em busca de maior reconhecimento de seu lugar no cenário político-administrativo. No Brasil, esse processo se deu com a redemocratização, em 1988, e a elaboração de uma Constituição Federal com base nas demandas de diferentes setores sociais.

Percebe-se ainda a valorização da experiência comunitária através da relação entre identificação com o lugar que se habita e a afinidade gerada pelos monumentos e demais bens culturais, desenvolvendo um compartilhamento sobre a noção de consenso entre os habitantes da cidade. Dar espaço e visibilidade aos diversos grupos sociais garantiria a unidade nacional a partir da exaltação da diversidade sociocultural da Nação.

Nesse sentido, o processo de descentralização administrativa viria a complementar o discurso consolidado no texto constitucional brasileiro. Com um maior espaço de atuação, ficaria mais fácil para as administrações locais atuarem no contato com os diferentes grupos da sociedade civil e implantarem os projetos de recuperação de sítios históricos. No contexto contemporâneo, a abertura de novos canais de diálogo pode ser compreendida como uma possibilidade de reconfigurar o passado e promover o futuro na representação das cidades.

A partir das considerações apresentadas, espera-se contribuir para a reflexão e o estabelecimento de novos modelos de gestão de sítios urbanos históricos mais democráticos e inclusivos. Como observado ao longo deste artigo, as intensas transformações urbanas tornam a participação da sociedade no processo de gestão de sítios históricos urbanos uma tarefa complexa, indo além dos limites dos impactos do setor turístico local. 


\section{Referências}

ANDRIOL0, Arley.

(2009). Entre a ruína e a obra de arte: psicossociologia da percepção da cidade histórica turística. Estudos de Psicologia, vol. 14, n² 2, maio-agosto/2009, p. 159-166. Disponivel em: http://www.scielo.br/pdf/ epsic/v14n2/a09v14n2.pdf. Acesso em: 30 abr. 2016.

BAHL, Miguel.

(2003). Perspectivas do turismo na sociedade pós-industrial. São Paulo: Rocca.

BAPTISTA, Luís Vicente; PUJADAS, Joan Josep. (2000). Confronto e entre posição: os efeitos da metropolização na vida das cidades. Fórum sociológico, 3/4, pp. 293-308.

BARREIRA, Irlys Alencar F.

(2010). Pulsações no coração da cidade: cenários de intervenção em centros urbanos contemporâneos. Caderno CRH, Salvador: EDUFBA, v. 23, $n^{\circ}$ 53, maio-agosto, pp. 255266.

BEEH0, Alison J.; PRENTICE, Richard.

(1997). Conceptualizing the experiences of heritage tourists: a case study of New Lanark World Heritage Village. Tourism management, Grã-Bretanha: Elsevier, v. 18, no. 2, pp. 75-87.

BRASIL.

(2007). Programa de Regionalização do Turismo - Diretrizes, p. 27.

BRUSADIN, Leandro Benedini.

(2005). Estudo da avaliação do Programa Nacional de Municipalização do Turismo PNMT na gestão do presidente Fernando Henrique Cardoso. Revista Hospitalidade, São Paulo, ano $2, \mathrm{n}^{\circ} 2,2^{\circ}$ semestre, pp. 87-111.

CARRIÓN, Fernando.

(2005). El centro histórico como proyecto y objeto de deseo. Revista eure, vol. XXXI, no 93 , Santiago de Chile: Chile, agosto, pp. 89-100.

CHOAY, Françoise.

(2002). A alegoria do patrimônio. 4. ed. São Paulo: Estação Liberdade - UNESP, São Paulo, 288p.
COHEN, J.; ARATO, Andrew.

(1992). Civic Society and Political Theory. Cambridge, Mass, MIT Press, 747p.

CRUZ, Rita de Cássia.

(2000). Política de turismo e território. São Paulo: Contexto.

DAGNIN0, Evelina (org).

(2000). Sociedade civil e espaços públicos no Brasil. São Paulo: Paz e Terra, 364p.

FORTUNA, Carlos (0rg.).

(1997). Cidade, Cultura e Globalização. Celta: 0eiras.

HARVEY, David.

(2005). Do administrativismo ao empreendedorismo: a formação da governança urbana no capitalismo tardio. A Produção Capitalista do Espaço. São Paulo: Annablume, p. pp.163-190.

HERNÁNDEZ, Francisca.

(2002). El patrimonio cultural: la memoria recuperada. Gijón: Ediciones Trea, 462p.

MCKERCHER, Bob; DU CROS, Hilary.

(2003). Testing a cultural tourism typology. The international journal of tourism research, Malden, MA: John Wiley \& Sons, v. 5, n $1, \mathrm{pp}$. 45-58.

MILANI, Carlos.

(2008). 0 princípio da participação social na gestão de políticas públicas locais: uma análise de experiências latino-americanas e europeias. Revista de Administração Pública. Rio de Janeiro: Editora FGV, vol. 42, $\mathrm{n}^{\circ} 3$, pp. 551- 579.

NAÇÕES UNIDAS.

(1948). Declaração dos Direitos do Homem, 7p.

OMT.

(1995). Compilación de las estadísticas del gasto turístico. Manual Técnico $\mathrm{N}^{\circ} 2,104 \mathrm{p}$.

PEIXOTO, Paulo.

(2003). Centros históricos e sustentabilidade cultural das cidades. Seminário - A cidade 
entre projectos e políticas. Faculdade de Letras da Universidade do Porto: Portugal, pp. 211226. Disponivel em: http://ler.letras.up.pt/ uploads/ficheiros/artig08511.pdf . Acesso em: 10 mar. 2017.

PEREIRA, Jaqueline de Olliveira.

(2000). Descentralização das políticas públicas em Turismo: análise do Programa Nacional de Municipalização do Turismo no Rio Grande do Norte - Natal, RN. Dissertação de Mestrado em Administração, UFRN, 126p.

PEREIRA, Paulo.

(2002). Património: Jogo de Identidades. In: BRITO, Lúcia Gonçalves (coord.). Gestão Urbana - Passado, presente e futuro. Parque Expo 98 SA - Unidade de Gestão Urbana: Lisboa, Julho, pp. 34-48.

PREDEBON, Eduardo Angonesi; SOUSA, Paulo Daniel Batista de.

(2003). As organizações, o indivíduo e a gestão participativa. II Seminário, Paraná: Unioeste, 2003. Disponivel em: http://www.unioeste. $\mathrm{br} / \mathrm{campi} /$ IISeminario/ver_artigo.pdf. Acesso em: 14 fev. 2015.

\section{SILBERBERG, Ted.}

(1995). Cultural tourism and business opportunities for museums and heritage sites. Tourism management, Grã-Bretanha: Elsevier, v. 16, n 5, pp. 361-365.

SMITH, Valene L.

(1989). Introduction. Hosts and guests: the anthropology of tourism. 2. ed. Philadelphia: University of Pennsylvania Press, pp. 1-17.
SOUZA, Celina.

(2004). Governos locais e gestão de políticas sociais universais. São Paulo em Perspectiva, São Paulo: Fundação Saede, vol. 18, pp. 2741.

TEIXEIRA, Elenaldo Celso.

(2001). 0 local e o global: limites e desafios da participação cidadã. 2. ed. São Paulo: Cortez, 244p.

TRIBE, John.

(1997). The indiscipline of tourism. Annals of tourism research, Grã-Bretanha: Elsevier, v. 24, no. 3, pp. 638-657.

URRY, John.

(1996). The tourist gaze: leisure and travel in contemporary societies. London: SAGE Publications, 175p.

VAINER, Carlos.

(2009). Pátria, empresa e mercadoria: a estratégia discursiva do Planejamento Estratégico Urbano. In: ARANTES, 0.; MARICATO, E.; VAINER, C. B. (orgs.). A Cidade do Pensamento Único. Desmanchando Consensos. 5. ed., Petrópolis: Vozes, pp. 75103.

\section{Recebido em}

julho de 2017

\section{Aprovado em}

agosto de 2019 